\title{
Multi-step Hydroforming Process And Wall Thickness Optimization of 5A02 Aluminum Alloy Five-Way Tube With Different Branch Diameter
}

\author{
Liming Wei \\ Nanchang Hangkong University \\ Xuefeng Xu ( $\nabla$ xfwinzy@163.com) \\ Nanchang Hangkong University \\ Yubin Fan \\ Nanchang Hangkong University \\ Ju Zhang \\ Nanchang Hangkong University \\ Congcong Yuan \\ Nanchang Hangkong University
}

\section{Research Article}

Keywords: Different diameter branch, Five-way tube, Hydroforming process, Wall thickness optimization

Posted Date: November 5th, 2021

DOI: https://doi.org/10.21203/rs.3.rs-1027514/v1

License: (c) (1) This work is licensed under a Creative Commons Attribution 4.0 International License. Read Full License

Version of Record: A version of this preprint was published at The International Journal of Advanced Manufacturing Technology on April 11th, 2022. See the published version at https://doi.org/10.1007/s00170-022-09192-2. 


\section{Abstract}

The different branch diameter of five-way tube affects the design of loading internal pressure in the hydroforming process, where the large-diameter branch is broken more easily than the small-diameter one due to the same ultimate stress of tube material in one-step forming method. Therefore, the first four-way and then five-way of multi-step forming (FFTF) method and the first three-way and then five-way of multistep forming (FTTF) method were proposed to fabricate the 5A02 aluminum alloy five-way tube with two kinds of branch diameters to avoid the burst of large-diameter branch tube. The finite element simulation of five-way tube hydroforming process shows that the height of small-diameter branch tube is lower and serious wrinkles appear at the large-diameter branch tube in the one-step forming and FFTF method. By optimizing the length of punch, a five-way tube with a big branch height and uniform wall thickness was obtained with the FTTF method. The approach of lengthening the punch in the experiment increased the height of formed branch and reduced the wall thickness reduction rate of five-way tube in FTTF method. Overall, the findings mentioned above can not only offer guide in creating five-way tube with excellent quality, but also be taken as reference to the hydroforming studies on multi-way tube in the future.

\section{Introduction}

With the rapid development of the aviation and automobile industry, the multi-way tube hydroforming process has been the focus of research ${ }^{[1]}$. The principle of hydroforming process is to form various complicated thin-walled hollow section parts by the combined action of mechanical load and hydro-static internal pressure ${ }^{[2,3]}$. Compared with the traditional forming technology, the part using hydroforming process has many advantages, such as lightweight, good structural integrity, avoiding secondary operation, and reducing waste $\mathrm{e}^{[4]}$.

In the hydroforming process, it is found that internal pressure, axial feed and friction are the main parameters that affect the forming effect ${ }^{[5]}$. Fvollertsen ${ }^{[6]}$ has summarized the estimation formulas of various process parameters of high pressure forming in T-shaped tubes and specifically given the estimation formulas of clamping force, axial feed force, reverse thrust punch force, and shaping pressure. Manabe and Amino ${ }^{[7]}$ confirmed with both finite element (FE) simulations and experiments that key process and material factors affect the tube wall thickness distribution. Optimizing the data in the hydroforming process to obtain higher branch height and more uniform wall thickness has always been the focus of research. Alaswad et al. ${ }^{[8]}$ compared the research results between single and bi-layered hydroforming processes under the same conditions, and concluded that the loading path should be optimized for superior control of the process because of complexity of the hydroforming process. Jang et al. ${ }^{[9]}$ found that internal pressure and axial feed determine the quality of deformed parts, and the equivalent static load method is used to optimize the loading path to prevent defects. Fiorentino et al. ${ }^{[10]}$ formed a Y-shaped piece by creating asymmetric conditions in the feed zone of the tube hydroforming process and utilizing a quasi-free model. Jirathearanat et al. ${ }^{[11]}$ evaluated the process design of hydroforming for Y-shaped tubes through finite element analysis (FEA) and experiment, and found that 
tube length is the important parameter affecting the formability of protrusion. In addition to the study of load path and internal pressure optimization, Xu et al. ${ }^{[12,13]}$ proposed to adjust the material flow by changing the friction coefficient in the asymmetric zone in the tube part, thereby avoiding wrinkling in Tshaped tube hydroforming. Moreover, Dong et al. investigated on the hydroforming process by mixing the hydroforming process with both artificial aging and heat treatment on aluminum alloys and obtained good results on formability issues ${ }^{[14]}$.

At present, the research on four-way tubes has also achieved certain results, which can be divided into Xtype four-way tubes and parallel double-branch type four-way tubes. Mehran and Kadkhodayan ${ }^{[15]}$ studied the optimization of load path in hydroforming of angled tubes which include $\mathrm{X}$ - and $\mathrm{Y}$-shaped tubes through statistical methods in conjunction with FEA and simulated annealing algorithms, and the quality of the final product containing the variance of tube thickness and height was improved significantly by using the optimization method. Olabi et al. ${ }^{[16]}$ used the LS-DYNA preprocessor and solver to establish a finite element model for the hydroforming of copper X-shaped double-layer tubes, and simulated the failure modes of $X$-shaped tube rupture and wrinkles and verified them with experiments. Majzoobi et al. ${ }^{[17]}$ study the effect of the branch end boundary condition on the product quality, and found the X-shape tube quality can be improved by application of a constraint such as spring in the branch of the hydroforming die.

However, some one-step forming of complex shape parts frequently appear the defects of wrinkling, cracking and uneven wall thickness in the hydroforming process. Therefore, the research of multi-step hydroforming is great significance. Cui et al. ${ }^{[18]}$ studied the manufacture of GH4169 expanded diameter T-shaped tubular parts and used four-step hydroforming to successfully overcome the problem of severe thinning in the traditional one-step hydroforming. Peng et al. ${ }^{[19,20]}$ proposed a multi-step process with preform procedure to improve the stress states in the protrusion to avoid the wrinkling and cracking defects, and sound components were produced.

There are more studies on T-shaped tube and four-way tube, but few studies on five-way tube. In the past, five-way tube was formed by welding multiple T-shaped tubes together. Because the tube blank is relatively long and the structure is complex, it is difficult to form the five-way tube. This paper proposes a multi-step forming method of five-way tube to eliminate the defects of large-diameter branch breaking during one-step forming and optimize the wall thickness and branch height. Finally, the results obtained are verified through experiments to prove that the proposed method is effective.

\section{Principle And Method Design Of Five-way Tube Hydroforming}

With similar principles to conventional tube hydroforming, the one of five-way tube hydroforming processes is that the tube blank is plastically deformed along the die cavity under the combined action of internal pressure $P$ and axial feed forces $F$ at both ends, as shown in Fig. 1. However, the five-way tube may have three branches with different diameters so that its pressure loading is complex according to 
Eq. (1)(2) ${ }^{[21]}$, in which the initial yield pressure $p_{s}$ and ultimate internal pressure increases with the decrease of diameter $d$. Therefore, the larger the diameter of branch is, the less its initial yield pressure $p_{s}$ and ultimate internal pressure is in the five-way tube hydroforming process. When the plastic deformation happens in the small-diameter branch (s-branch), its ultimate internal pressure may lead to the fracture in the large-diameter branch (I-branch). The relationship between the above variables can be expressed by the following equations:

$$
\begin{aligned}
& P_{s}=\sigma_{s} \frac{2 t}{d} \\
& P_{b}=\sigma_{b} \frac{4 t}{d}
\end{aligned}
$$

Where $P_{s}$ is the initial yield pressure, $\sigma_{s}$ is the yield strength of the material, $P_{b}$ is the ultimate internal pressure, $\sigma_{b}$ is the Tensile strength of the material, $t$ is the wall thickness of the tube, $d$ is the diameter of the tube.

In this study, the geometry of 5A02 aluminum alloy five-way tube was shown in Fig. 2. Its main tube has a diameter of $40 \mathrm{~mm}$ and a wall thickness of $1 \mathrm{~mm}$. And there is a $32 \mathrm{~mm}$ diameter branch tube(s-branch)in the middle of the upper side and two branches[l-branch \with diameter of $40 \mathrm{~mm}$ are distributed symmetrically at an interval of $160 \mathrm{~mm}$. In the hydroforming process, owing to the different flow states of the material, the five-way tube is divided into guiding zone, transition zone, expansion zone, and intermediate zone. Based on the Eq. (1)(2) and structural characteristics of five-way tube, three different forming schemes were designed as follows:

1) One-step forming method: all three branches were formed in one step. Its schematic diagram was shown in Fig. 3a.

2) The first four-way and then five-way multi-step forming(FFTF) method: Two of the branches are formed in the first step and then the remaining branch of the four-way tube is formed in the five-way tube die, as shown in Fig. a. However, the preformed part comprises four-way tube with different diameter branches and four-way tube with the same diameter branches, as illustrated in Fig. 3b and c.

3) The first three-way and then five-way of multi-step forming (FTTF) method: a s-branch tube was formed in the first step and then the two I-branch tube were manufactured in the second step, as shown in Fig. 3a and d.

\section{Materials And Numerical Simulation 3.1 Material properties}

The material of the five-way tube in this article is $5 \mathrm{~A} 02$ aluminum alloy and its mechanical properties are shown in Table 1. The power-law plastic model was adopted in this numerical simulation, as illustrated in 
formula (3).

$\sigma=\mathrm{K} \varepsilon^{\mathrm{n}}(3)$

Where $\sigma$ is the true stress, $K$ is the strength coefficient, $\varepsilon$ is the true strain, and $n$ is the strain hardening exponent.

Table 1 Material properties of 5A02 aluminum alloy

\section{Elastic modulus/GPa}

Poisson's radio

Yield strength/MPa

Strength coefficient (K-value) / $\mathrm{MPa}$

Strain-hardening exponent (n-value)

Tensile strength/MPa

Elongation
70

0.33

85

502

0.35

202

\subsection{Finite element model}

Dynaform 5.9 software was used to simulate the hydroforming process of five-way tube with different branch diameter. The influence of the forming methods, the lengthened punch on the deformation of tube was predicted by simulation. The simplified models mainly consisted of four parts: die, punch, plug and tube as shown in Fig. 4. The dies are defined as rigid bodies, and the tube is defined as Belytschko-Tsay shell elements. The initial length of the tube blank is $500 \mathrm{~mm}$, and the coefficient of friction between the tube and die is selected as 0.1 . It can be got that the total axial feeding on each side of tube end is $200 \mathrm{~mm}$ according to the principle of constant volume. At the same time, the theoretical yield internal pressure and ultimate internal pressure can be calculated from the Eq. (1) and (2). Based on overall consideration, two loading paths of internal pressure were selected due to the different forming internal pressure of I-branch tube and s-branch tube, corresponding to curves \#1 and \#2 in Fig. 5, respectively.

To investigate the effect of branch tube diameter on five-way tube forming, the finite element models were established, including a five-way die model, a four-way die model with the same diameter branches, four-way die model with different diameter branches and three-way tube model, as shown in Fig. 5. In the numerical simulation of one-step hydroforming of five-way tube, the axial feed of the punch is $200 \mathrm{~mm}$, and the internal pressure loading path \#1 and \#2 were selected to compare the results. In the multi-step forming method of five-way tube, the axial feed of left and right pushers in the numerical simulation of the first step preforming and the second step five-way tube forming is set to $70 \mathrm{~mm}$ and $30 \mathrm{~mm}$, respectively. In addition, the internal pressure loading path is determined by the diameter of the branch tube. The internal pressure loading path \# 1 is suitable for s-branch while the internal pressure loading path \# 2 is chosen for the forming of the I-branch. 


\section{Numerical Simulation Results}

\subsection{Effect of different methods on five-way tube forming 4.1.1 One-step forming method}

In the numerical simulation of one-step forming method, the thickness contours of five-way tube under different internal pressure loading are obtained, and the five-way tube were wrinkled and cracked, and the s-branch were not thoroughly formed, as shown in Fig. 5 . The results show that the height of s-branch is low due to the low internal pressure, and the l-branch formed first impedes the flow of material to the middle and causes wrinkling when the internal pressure loading path \# 2 is used. In addition, the internal pressure of loading path \# 1 rises rapidly, and the material supply is problematic to sustain the l-branch tube bulging, which causes the s-branch to be thinned and broken before it is formed. Therefore, the forming pressure of the branch tube is affected by the diameter, different diameter branches are formed at the same time, the forming pressure of the s-branch is easy to cause the rupture of the I-branch.

\subsubsection{FFTF method}

Since the one-step forming method could not generate qualified parts, the multi-step forming method was selected to further the investigation of the five-way tube forming process. In the numerical simulation using the FFTF method, the parts simulated in the first step of preforming are four-way tube with different diameter branches and four-way tube with the same diameter branches, respectively. As shown in Fig. 6a and $b$, the simulation results of the four-way tube with different diameter branches were analyzed, the Ibranch under internal pressure loading path \#1 was thinned and ruptured due to excessive ultimate internal pressure, resulting in the failure of the s-branch to continue forming; the wrinkling of the part under internal pressure loading path \#2 is due to the accumulation of material at the formed I-branch. In addition, the longer guide zone on the right side of the four-way tube causes the material to thicken the main tube first, resulting in less material flowing into the s-branch. The results of the simulation indicate that it is hard to obtain qualified parts for four-way tube with diameter branches under different internal pressure loading paths.

In the simulation results of the same diameter four-way tube, the height and thickness of the two major branches of the preformed part meet the requirements, as shown in Figure 7a. However, in the second step of five-way tube forming, the massive branch tube wrinkles and the s-branch tube thin severely, as shown in Fig. 7b. Because there are I-branches on both sides of the final formed blank, punch feeding will cause the material to accumulate wrinkles at the l-branches and finally make it hard to recharge the material of the intermediate branches to crack. In this section, the simulation results are discussed. It becomes obvious that the problem of five-way tube in multi-step forming lies not only influenced by the internal pressure but also the distribution structure needs to be considered.

\subsubsection{FTTF method}


The simulation results of FTTF method are shown in Fig. 8, the internal pressure loading path \#1 in the three-way tube preforming satisfies the intermediate s-branch tube forming with the absence of defects. In Fig. 8b, the reason for the well-formed five-way tube is the location of the s-branch in the middle, which has almost no effect on the forming of the l-branch. In addition, the symmetrical structure provides convenient material replenishment, and the reasonable loading internal pressure gives fully shaped two branches. Overall, the simulation results from the analysis of the three methods indicate that the five-way tube hydroforming is influenced by the internal pressure and the branch forming sequence, with only the FTTF method eventually forming a complete part.

\subsection{Effect of punch length on five-way tube forming}

The five-way tube manufactured by the FTTF method are subject to poor branch height and uneven thickness distribution, thus the process requires optimization. In the first step of preforming the s-branch, the thickening of the main tube due to the excessive length of the initial tube blank, leads to difficulty in forming the l-branch in the second stage, and its tendency to wrinkle. Consequently, a punch with an outer diameter equal to the tube blank's inner diameter is designed to investigate the effect of the punch length on the forming of the five-way tube. In order to avoid interference between the left and right punch, the length in the simulation of the three-way tube is designed to be $140 \mathrm{~mm}$ and the diameter is $38 \mathrm{~mm}$, as shown in Figure 9.

According to the simulation results of three-way tube preforming, the effect of different length punches on it is compared, as shown in Fig. 8a and Fig. 10a. The results showed that the branch height of the three-way tube preformed by conventional punches was low, and the thickness of the branch end was severely thinned. In contrast, the branch height of the three-way tube with the lengthened punch is remarkably higher, and the branch end is more fully shaped. In order to visualize the wall thickness distribution of the three-way tube under different punches, the wall thickness data for different zones from the simulation results were plotted as Fig. 11. It could be observed that the wall thickness of the three-way tube with conventional punches is heavily thickened in the guiding zone, especially at the end of the main tube where the material builds up. Whereas, the material in the transition and expansion zones is rarely replenished, causing thinning and rupture of the s-branch and difficulty in final step forming. On the contrary, the wall thickness of the three-way tube affected by the lengthened punch tended to increase in the guide zone, and the wall portion near the transition zone had a stronger increase in thickness due to the absence of punch support, which also means that the branch is able to be formed higher.

In addition, stocking sufficient material in the intermediate zone of the preformed three-way tube facilitates uniform wall thickness distribution of the final formed five-way tube. Due to the fact that the punch feed only provides material replenishment on one side of the l-branch during the final five-way tube forming process, the other side is replenished by thinning the tube wall in the intermediate zone. Fig. 10b shows the simulation results of the final forming, all the branches are well-formed without thinning and rupture. In brief, the use of lengthened punches in the preforming stage could enhance the forming height 
of -branch tube, and the wall thickness distribution of the three-way tube affects the quality of the final forming of the five-way tube.

\section{Experimental Validation And Analysis}

In order to validate the reliability of the hydroforming simulation of the five-way tube, experimental studies on its forming method and process optimization are conducted. The tube hydroforming equipment is shown in Fig. 12, including the main cylinder, the horizontal cylinders, the pump and the supercharger. According to the experimental requirements of the FTTF method, a three-way tube forming die and a five-way tube forming die were prepared, where the lengthened punch was obtained by using a threaded connection extension on a conventional punch, as shown in Figure 13. The loading path of internal pressure and punch feed used in the experiment is the same as that of numerical simulation. Fluorosilicone grease was used as lubricant in the experiment, and the friction coefficient was 0.1.

The experimental results of preforming with lengthened punch are shown in Fig. 14. It was observed that the surface quality of the three-way tube was superior without wrinkling, and the branch tube reached up to $23.8 \mathrm{~mm}$. Afterwards, the part was cut down the center of the radial direction and the thinnest section was measured at the top of the branch, with a maximum thinning rate of $18 \%$. At the same time, the data was collected and organized to obtain the wall thickness distribution curve illustrated in Figure 15. Compared with the wall thickness distribution curve of the part using the lengthened punch in Figure 11, the two cases are basically identical. Nevertheless, the three-way tube in the experiment has a broader wall thickness than the simulated one. Overall, the results of the preforming experiments showed that lengthening the punch allowed the tube blank material to flow toward the middle part of the tube, thus forming a taller branch and stocking the material for the next experiments.

In the final forming experiments of five-way tube, the formability of the tubes is reduced due to the work hardening that occurs in the three-way tube during the preforming process. Therefore, the preforms were annealed before the final experiments to eliminate their internal stresses. The experiment results are shown in Fig. 16. It is observed that the five-way tube without wrinkles and the branches are well-formed, especially the large and small branches with heights of 25.2 and $26.9 \mathrm{~mm}$. In order to deeply investigate the quality of the five-way tube forming, the thickness distribution curves of the I-branch side and the sbranch side were plotted separately, as shown in Fig. 17. It can be seen that the wall thickness increase of the s-branch section is larger due to the fact that most of the material on the upper side of the tube blank accumulates in the guide area with the feed of the punch during the final forming experiment. Although thickening also occurred in the guiding zone of the l-branch section on the lower side, it appears that the thickness distribution on both sides of the branch was basically similar and that there was an absence of thinning in the intermediate zone of the part. From the result of simulation and experiment, it can be seen that the FTTF method and lengthened punch of the simulation result agrees well with that of experiment. Although there is a tiny difference between the simulation and the experiment, the variation tendency is the same. 


\section{Conclusion}

1. The article simulated the one-step forming method, FFTF method and FTTF method. Results has shown that defects such as wrinkle and raptures can be found in one step forming and FFTF forming methods. But the FTTF can make it possible to form the desirable five-way tube and prove validity of forming methods through the experiments.

2. The lengthened punch has greatly impacted branch height and wall thickness distribution of preformed three-way tubes and made it easier for the material flow by comparison with conventional punch, creating higher branch tubes and preformed three-way tube with evenly distributed wall thickness. Meanwhile, the lengthened punch can allow more materials to flow to the middle part of tube blank, storing enough margins of feeding supplement for the five-way tube forming experiments.

3. Research on the hydroforming methods of five-way tube has provided a knowledge of the forming sequence designed according to the position of branch tubes in the process of multi-step forming. Meanwhile, internal pressure of the forming branch tubes decreases as the diameter increases, and therefore different internal pressure of forming should be required in branch pipes with different diameters. The findings mentioned above can not only offer guide in creating five-way tube with excellent quality, but also be taken as reference to the hydroforming studies on multi-way tube in the future.

\section{Declarations}

Acknowledgements The authors thank the financial supports from the National Natural Science Foundation of China with Grant (NO.51975267) and National Science and Technology Major Project of China (No. J2019-VII-0014-0154).

Code availability Not applicable

Author contribution Liming Wei: writing, experiment. Xuefeng Xu: conceptualization, methodology. Yubin Fan: writing-review, validation. Ju Zhang: formal analysis, validation. Congcong Yuan: software.

Funding This work was supported by the National Natural Science Foundation of China with Grant (NO.51975267) and National Science and Technology Major Project of China (No. J2019-VII-0014-0154).

Data availability All the data have been presented in the manuscript.

Ethics approval Not applicable.

Consent to participate Not applicable.

Consent for publication Not applicable

Competing interests The authors declare no competing interests. 


\section{References}

1. Muammer K, Taylan A (2001) An overall review of the tube hydroforming (THF) technology. Journal of Materials Processing Tech 108(3):384-393

2. Colpani A, Fiorentino A, Ceretti E (2020) Characterization and optimization of the hydroforming process of AISI 316L steel hydraulic tubes. The International Journal of Advanced Manufacturing Technology 107(3):293-309

3. Kim BJ, Van Tyne CJ, Lee MY, Moon YH (2006) Finite element analysis and experimental confirmation of warm hydroforming process for aluminum alloy. Journal of Materials Processing Tech 187:296-299

4. Zhang SH (1999) Developments in hydroforming. Journal of Materials Processing Tech 91(1):236244

5. Chen M, Xiao X, Tong J, Guo H, Wen J (2018) Improvement of formability in T-shaped tube hydroforming by a three-stage punch shape. Springer London 95(5):2931-2941

6. Vollertsen F (2001) State of the Art and Perspectives of Hydroforming of Tubes and Sheets.Journal of Materials Science \& Technology(03):321-324

7. Manabe K, Amino A (2002) Effects of process parameters and material properties on deformation process in tube hydroforming. J Mater Process Technol 123(2):285-291

8. Alaswad A, Benyounis KY, Olabi AG (2011) Finite element comparison of single and bi-layered tube hydroforming processes. Simul Model Pract Theory 19(7):1584-1593

9. Jang HH, Lee Y, Park GJ (2016) Optimization of the loading path for the tube-hydroforming process. Proceedings of the Institution of Mechanical Engineers, Part D: Journal of Automobile Engineering 230(12):1605-1623

10. Fiorentino A, Ceretti E, Braga D, Marzi R (2010) Friction in asymmetric feeding tube hydroforming. IntJ Mater Form 3(1):275-278

11. Jirathearanat S, Hartl C, Altan T (2004) Hydroforming of Y-shapes-product and process design using FEA simulation and experiments. J Mater Process Technol 146(1):124-129

12. Xu X, Wu K, Wu Y, Jie X, Fu C (2019) A novel lubrication methodfor hydroforming of thin-walled aluminum alloy T-shaped tube. IntJ Adv Manuf Technol 102(5):2265-2273

13. Yuan C, Xu X, Fan Y, Huang L (2020) Numerical and experimental studies on thin-walled aluminum alloy tube hydroforming using differential lubrication method. Appl Phys A Mater Sci Process 126(10):572-596

14. Dong GJ, Bi J, Du B, Chen XH, Zhao CC (2020) Research on AA6061 tubular components prepared by combined technology of heat treatment and internal high pressure forming. Journal of Materials Processing Tech 242:126-138

15. Kadkhodayan M, Moghadam AE (2013) Optimization of load paths in X-and Y-shaped hydroforming. IntJ Mater Form 6(1):75-91 
16. Olabi AG, Alaswad A (2011) Experimental and finite element investigation of formability and failures in bi-layered tube hydroforming. Adv Eng Softw 42(10):815-820

17. Majzoobi GH, Farhoudi HR, Shirazi A (2012) An Investigation into Hydroforming of an X-Shape Pipe Connection. Adv Mater Res 1614:15-20

18. Cui X, Teng B, Yuan S (2021) Hydroforming process of complex T-shaped tubular parts of nickelbased superalloy. CIRP J Manufact Sci Technol 32:476-490

19. Peng J, Zhang W, Liu G, Zhu S, Yuan S (2011) Effect of internal pressure distribution on thickness uniformity of hydroforming Y-shaped tube. Transactions of Nonferrous Metals Society of China $21: s 423-s 428$

20. Liu G, Peng J, Wang X, Zhu S, Yuan S (2011) Effects of Preform on Thickness Distribution of Hydroformed Y-Shaped Tube. Adv Mater Res 1165:2796-2800

21. Jirathearanat S (2004) Advanced methods for finite element simulation for part and process design in tube hydroforming. Dissertation Abstracts International 1495:65-03

\section{Figures}

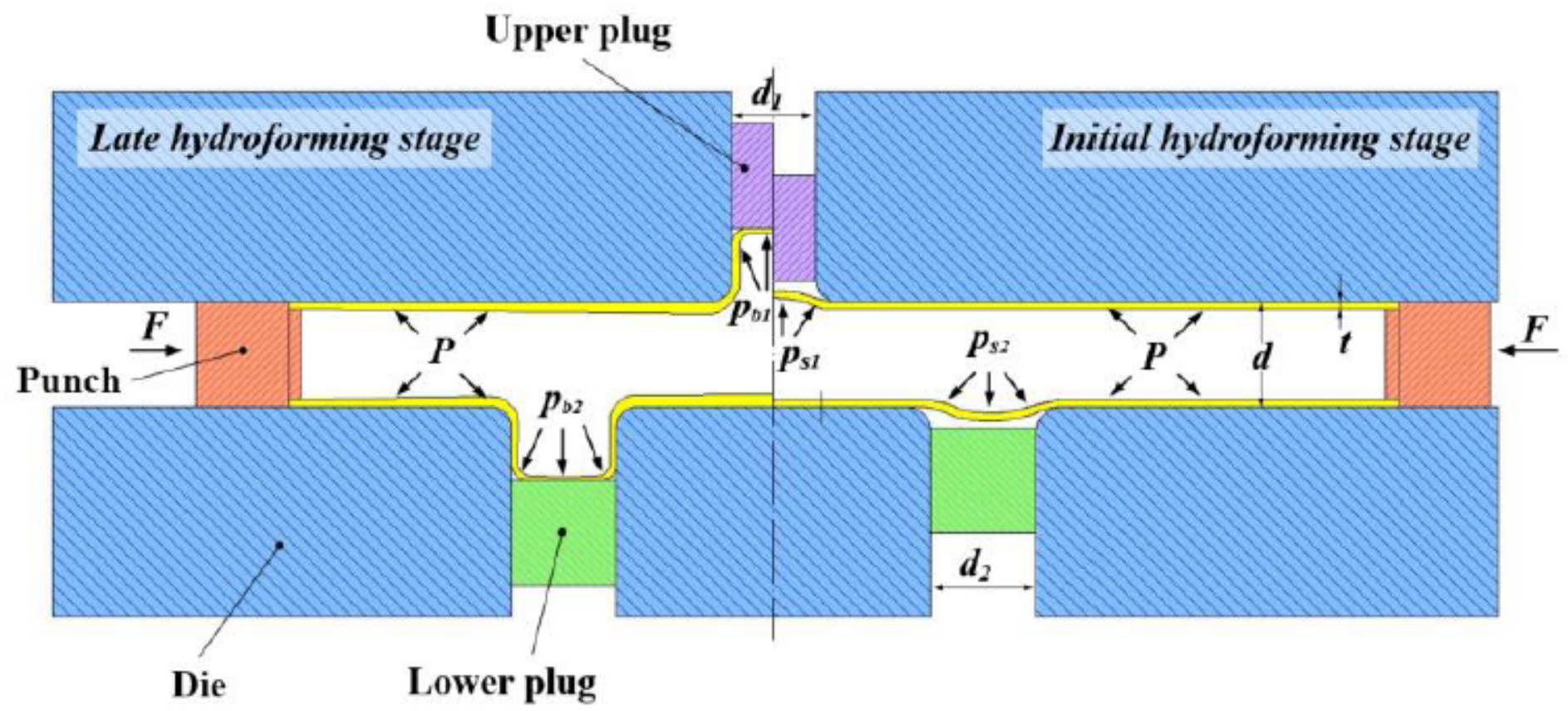

Figure 1

Principle of five-way tube hydroforming 


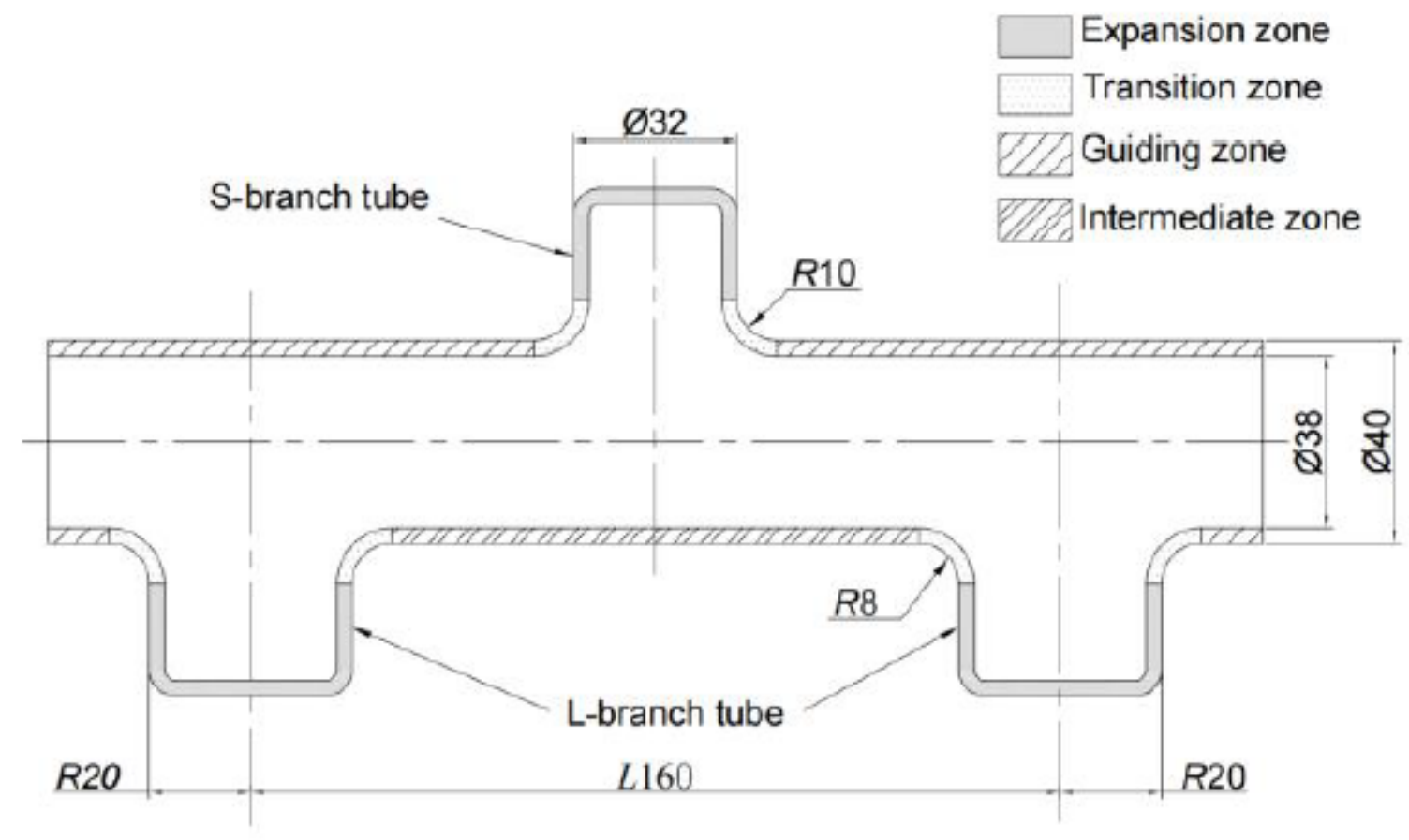

Figure 2

Geometry of the five-way tube

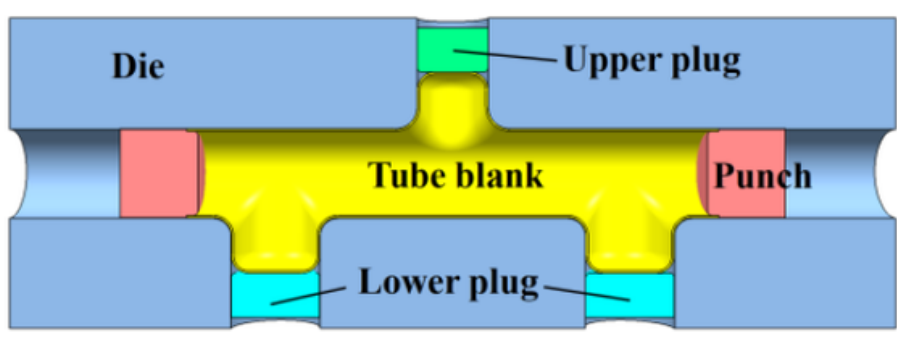

( a )

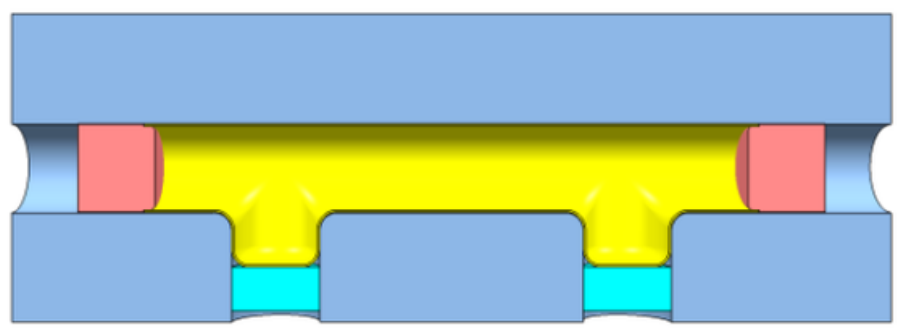

(c)

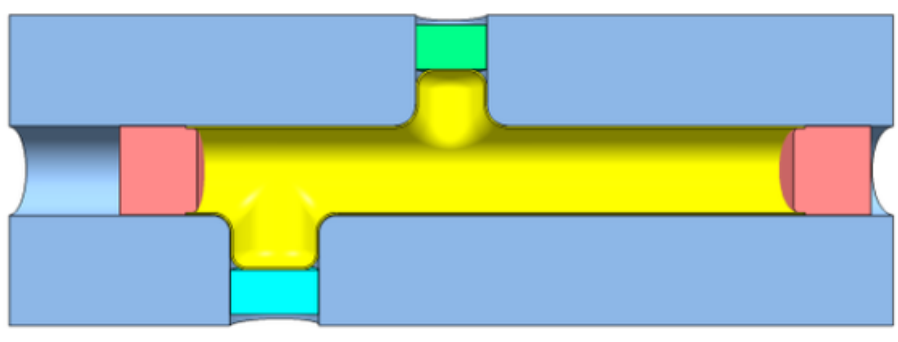

( b )

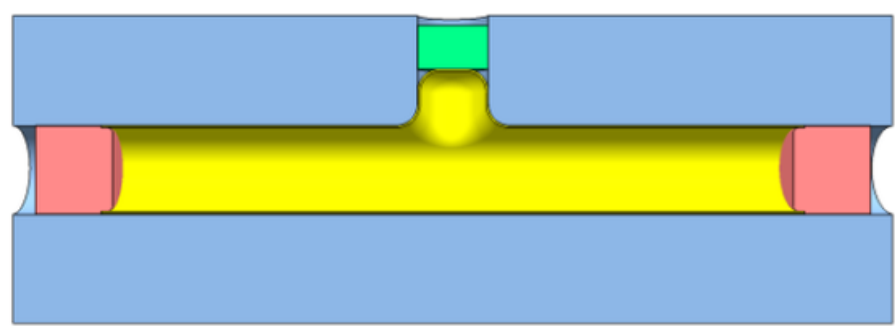

( d )

Figure 3

Different methods of five-way tube hydroforming die ( a ) Five-way tube (b) Different diameter four-way tube (c) Same diameter four-way tube die ( d) Three-way tube die 


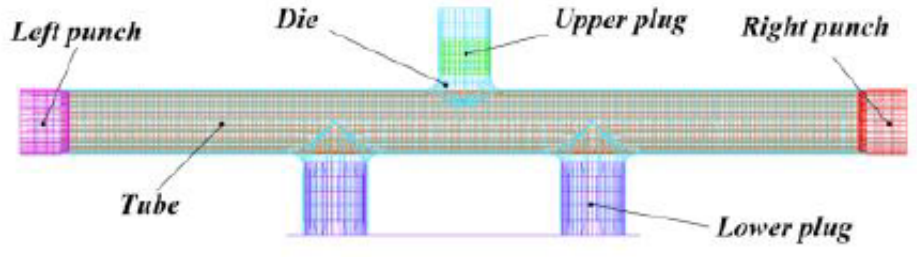

(a)

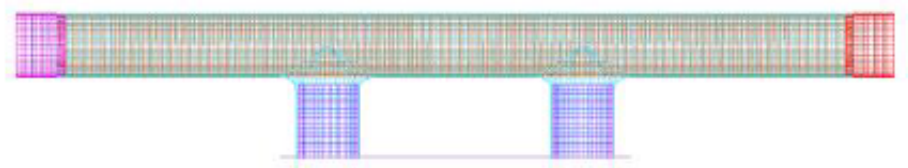

(c)

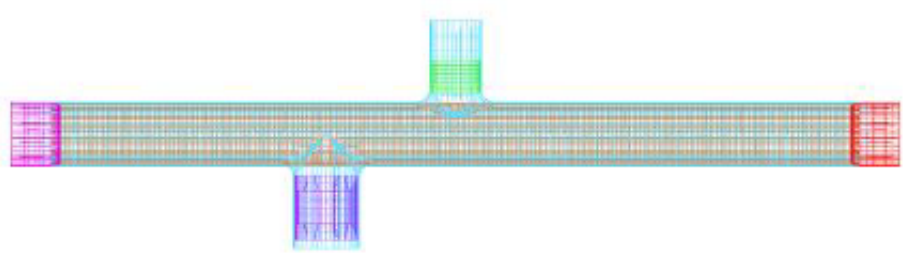

(b)

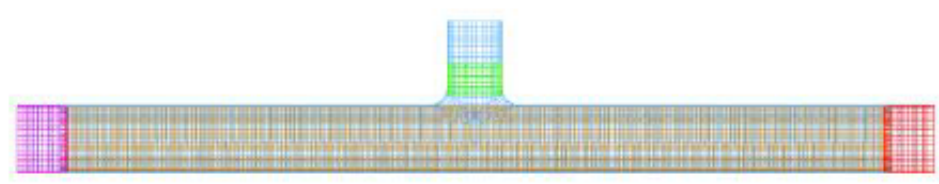

(d)

\section{Figure 4}

Finite element model (a) Model of five-way tube (b) Model of four-way tube with different diameters (c) Model of four-way tube with same diameters (d) Model of three-way tube

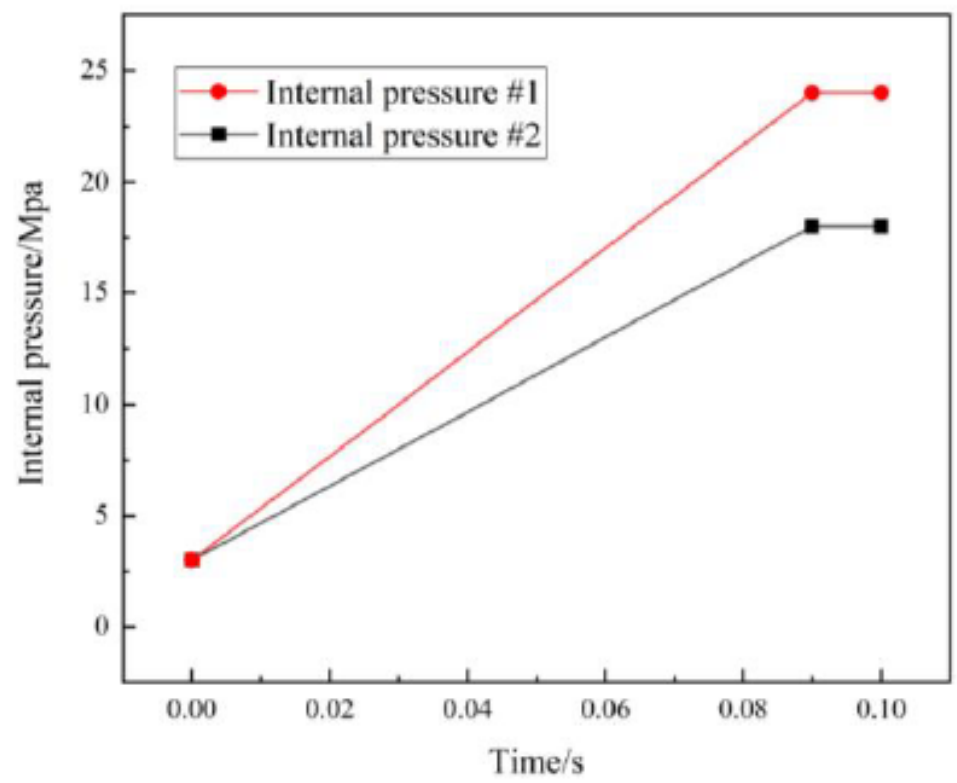

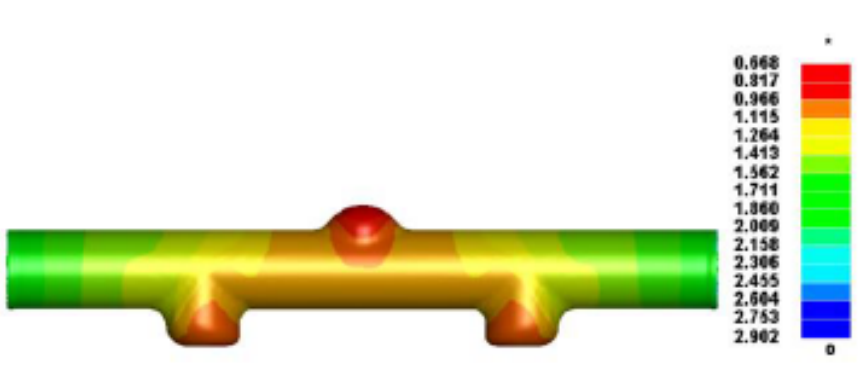

(a)

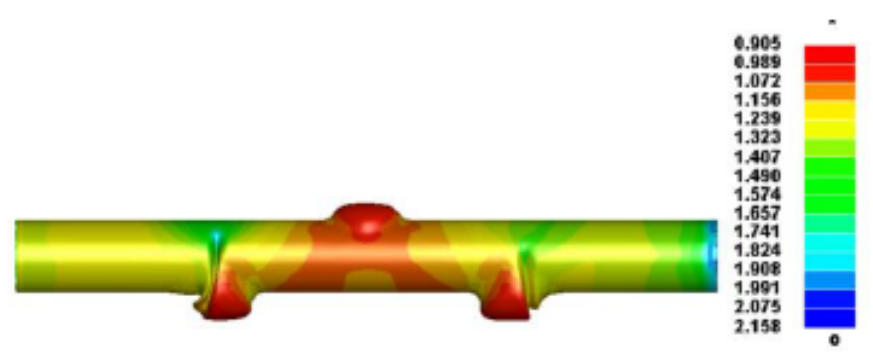

(b) 
Figure 5

Loading path of the internal pressure of five-way tube hydroforming Wall thickness distribution contour of parts in one-step forming method (a) Internal pressure loading path \# 1 (b) Internal pressure loading path \# 2

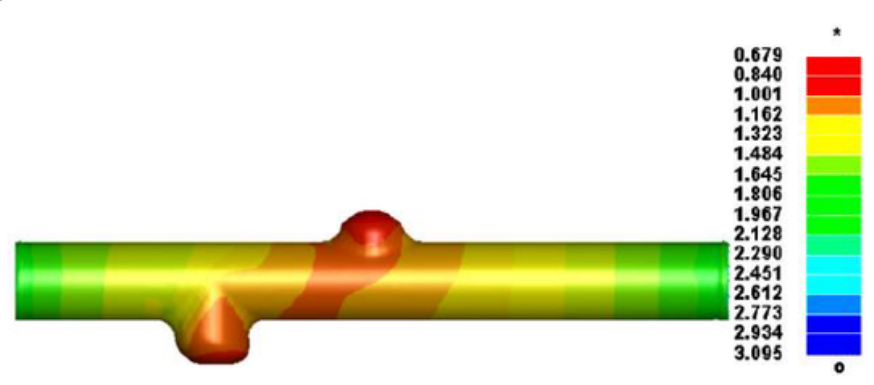

(a)

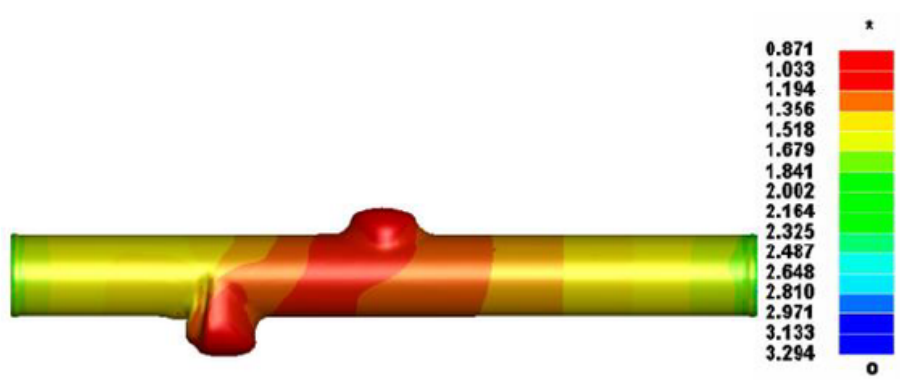

(b)

Figure 6

Wall thickness distribution contour of four-way tube with different diameter branches (a) Internal pressure loading path \# 1 (b) Internal pressure loading path \# 2

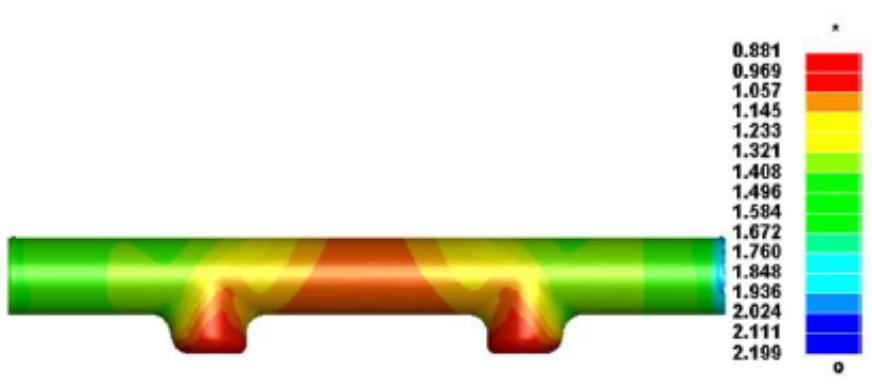

(a)

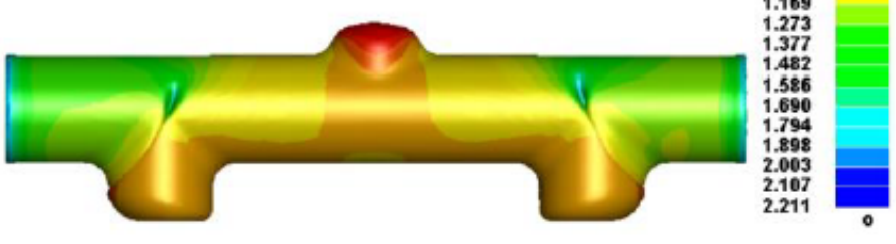

(b)

\section{Figure 7}

Wall thickness distribution contour of parts in FFTF method (a) Internal pressure loading path \# 2 (b) Internal pressure loading path \# 1

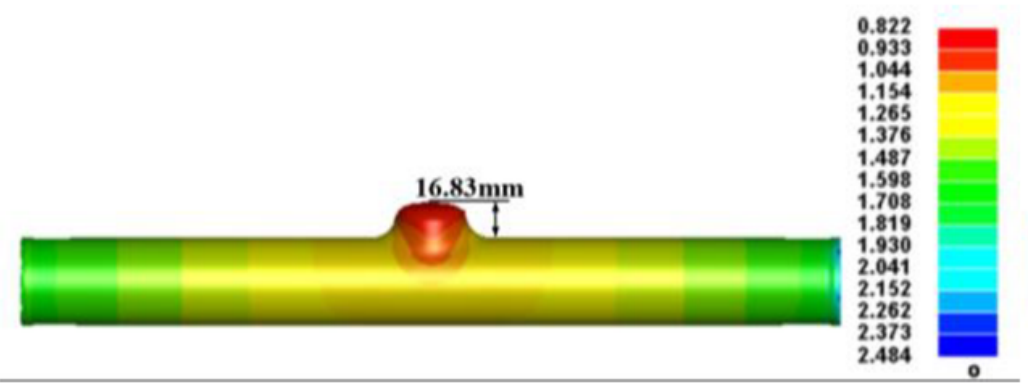

(a)

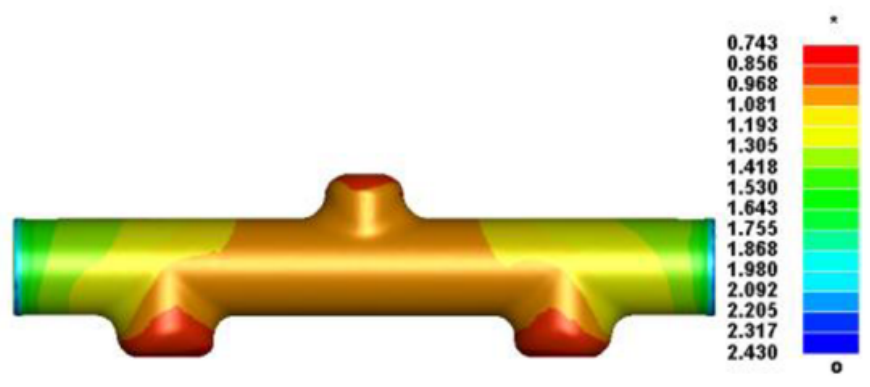

(b)

Figure 8 
Wall thickness distribution contour of parts in FTTF method (a) Internal pressure loading path \# 1 (b) Internal pressure loading path \# 2

\section{Conventional punch}

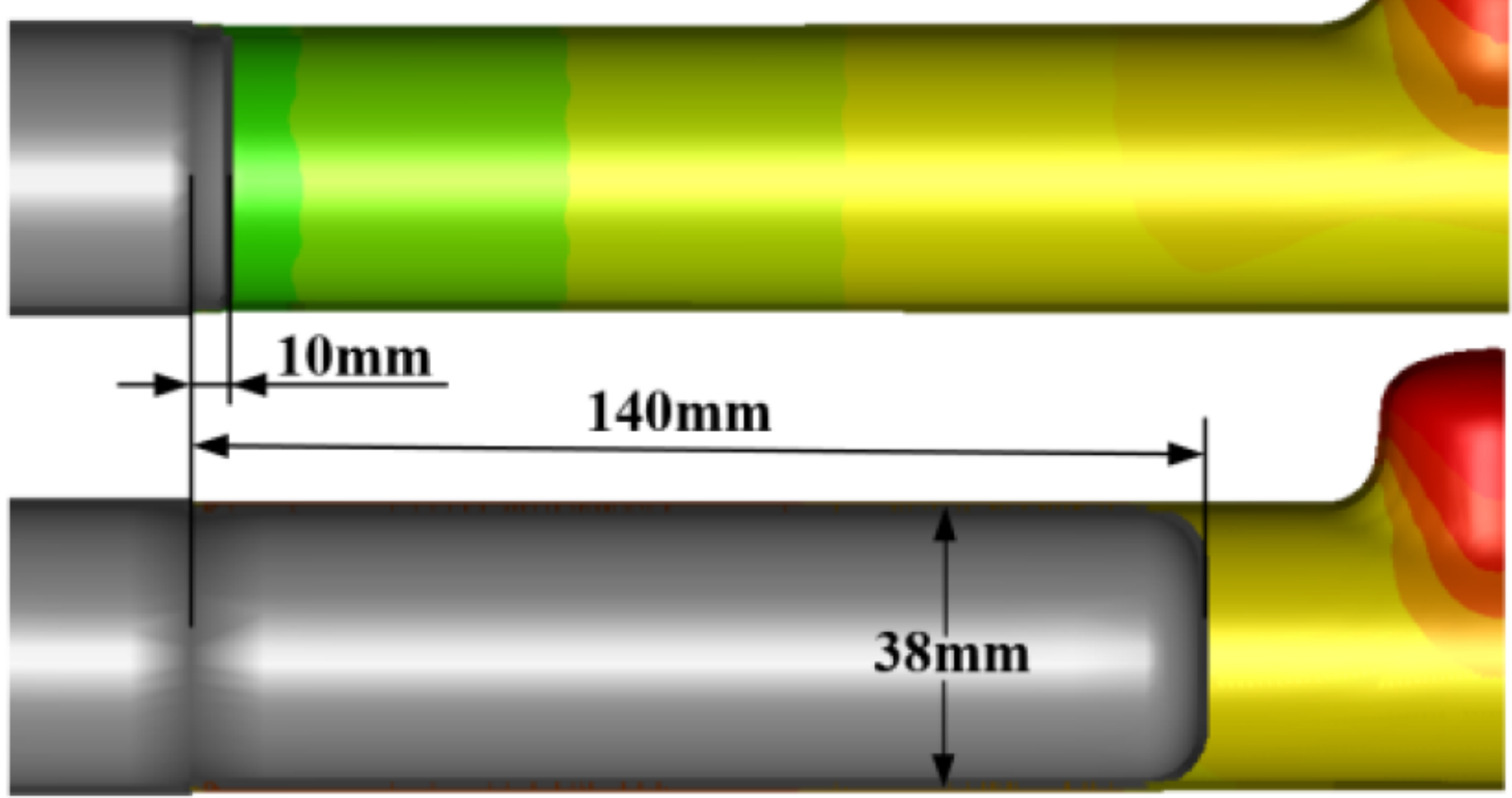

\section{Lengthened punch}

Figure 9

Lengthened punch and conventional punch sizes

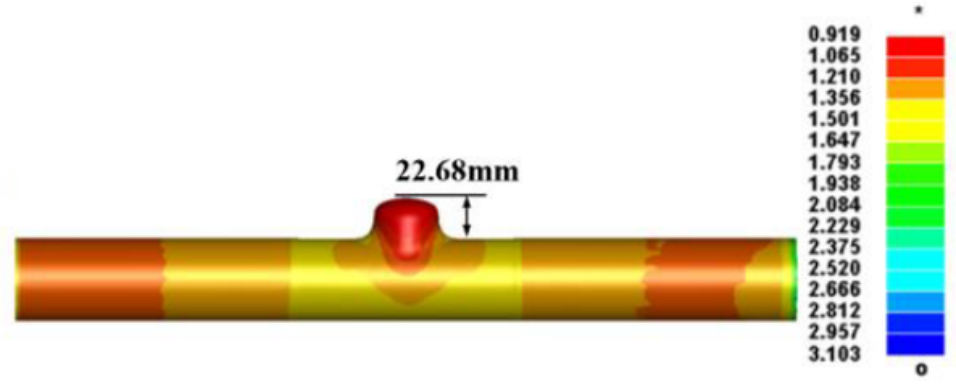

(a)

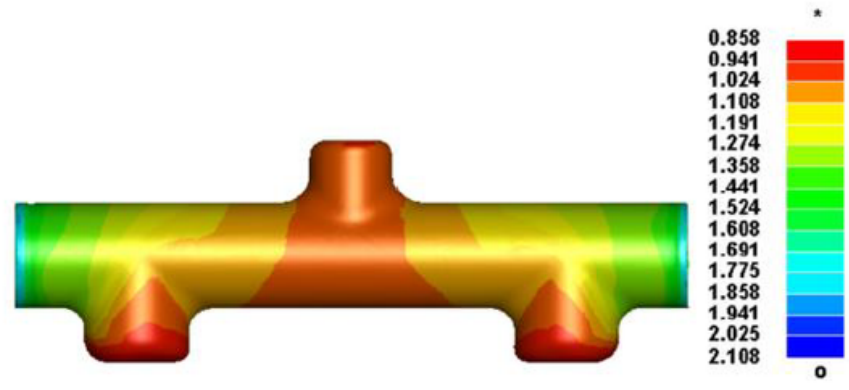

(b)

Figure 10

Wall thickness distribution of parts using lengthened punches in the FTTF method (b) Internal pressure loading path \# 1 (b) Internal pressure loading path \# 2 


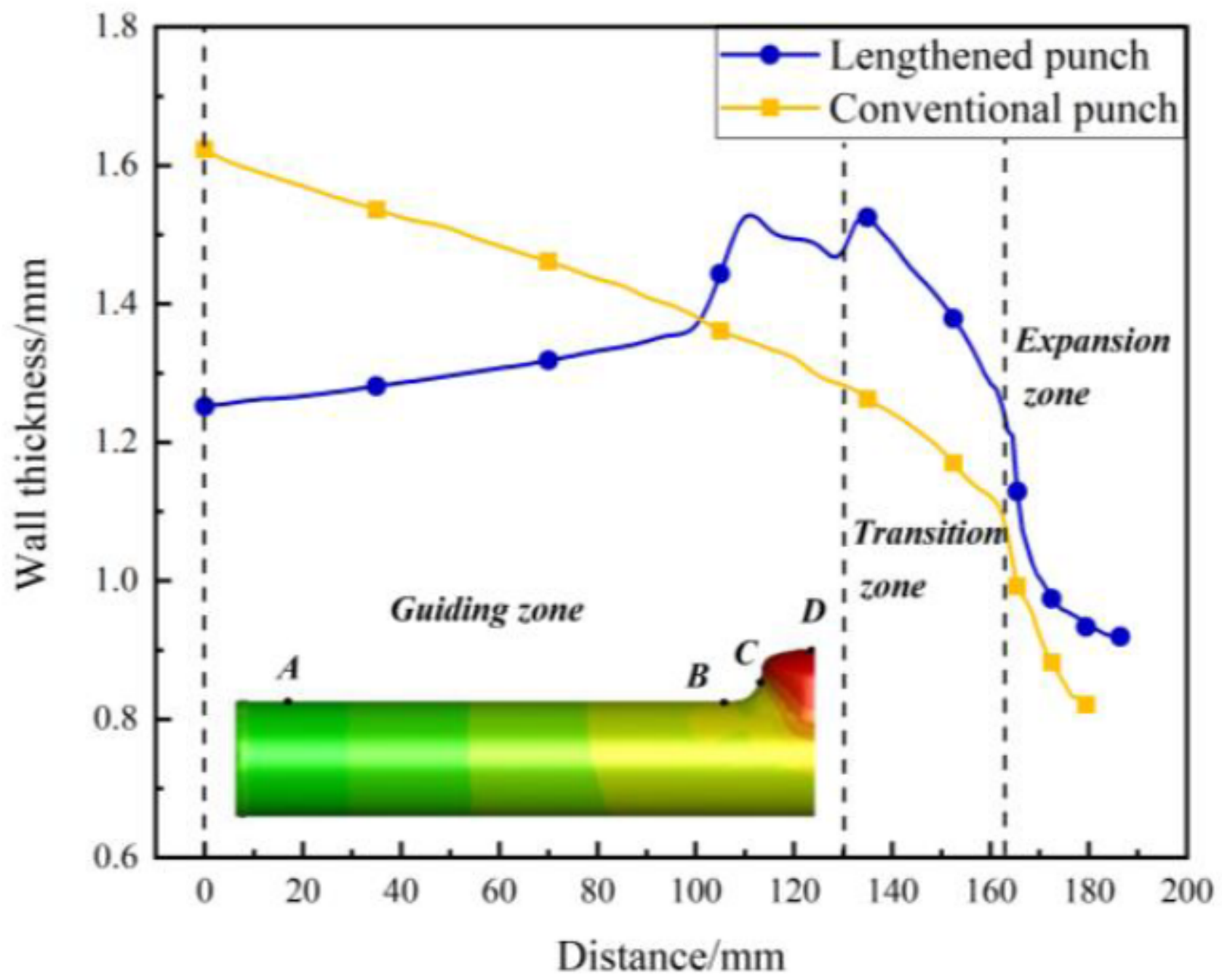

Figure 11

Three-way tube wall thickness distribution using different punches 


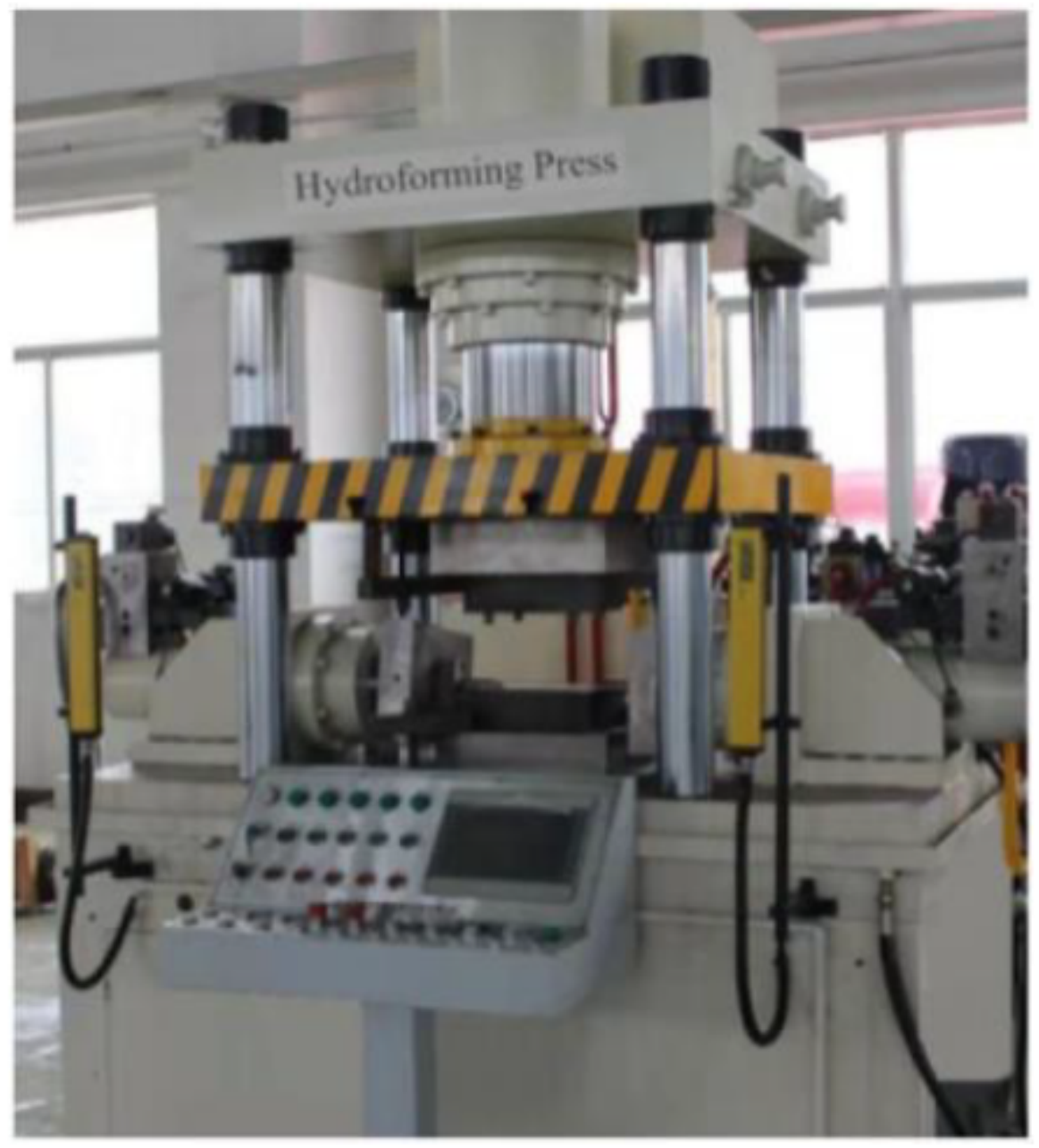

Figure 12

Internal high pressure forming machine 


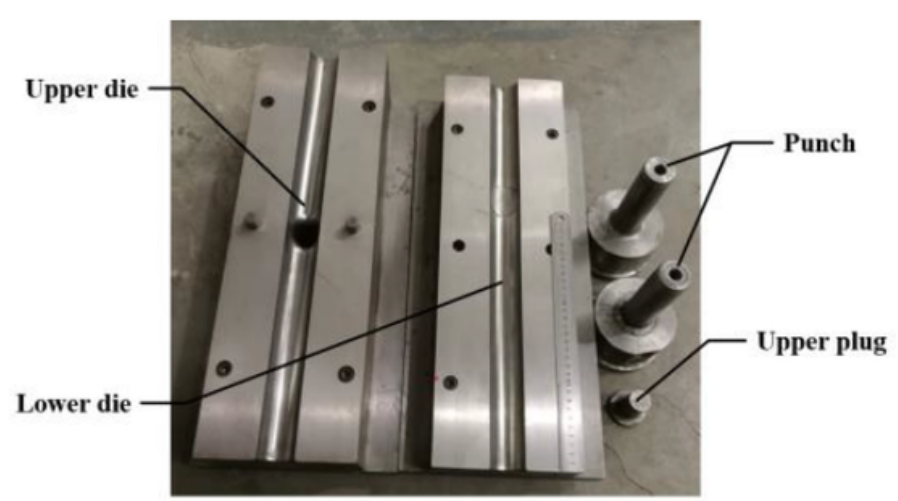

(a)

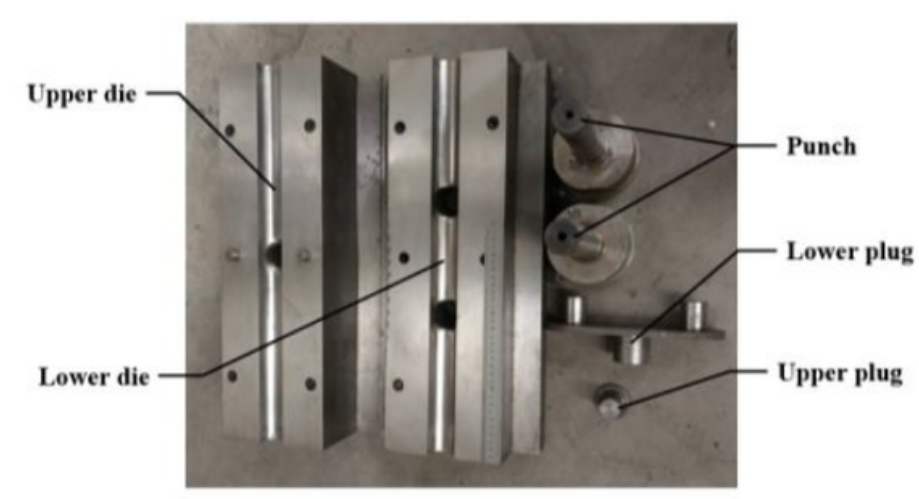

(b)

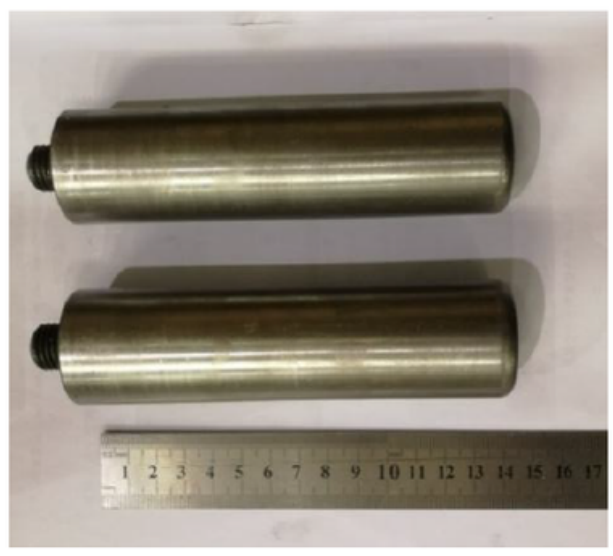

(c)

\section{Figure 13}

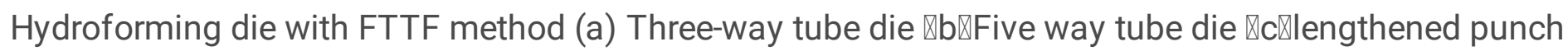

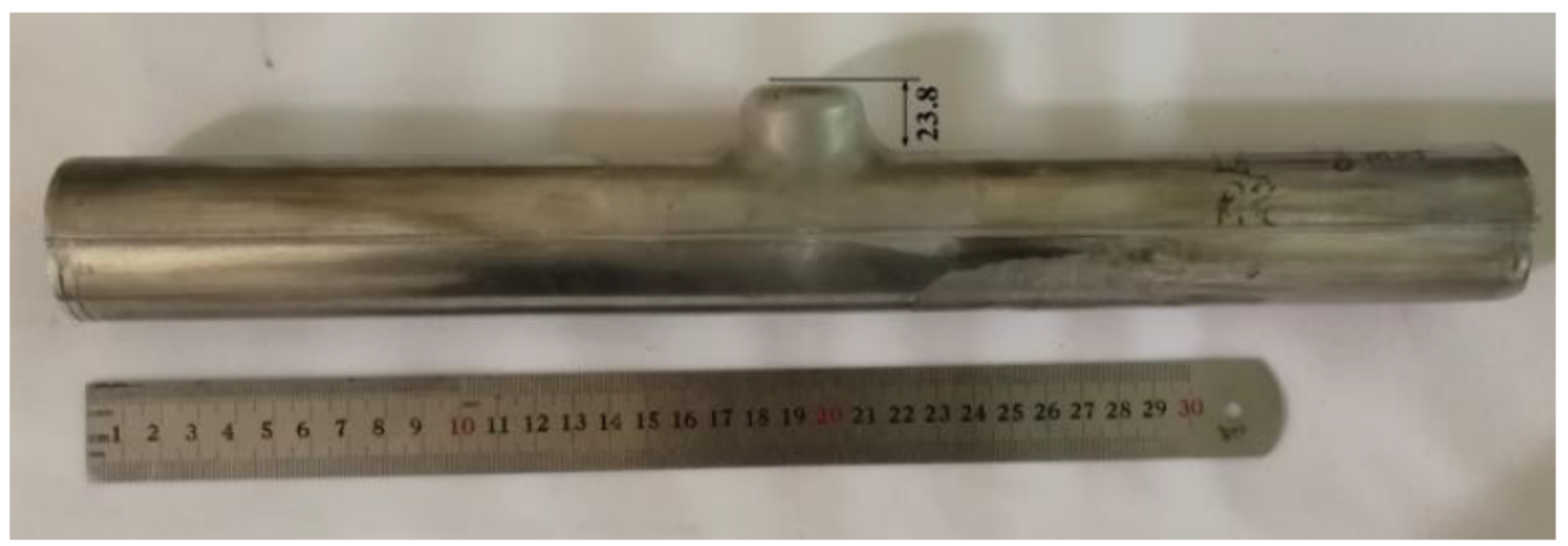

Figure 14

Preformed three-way tube 


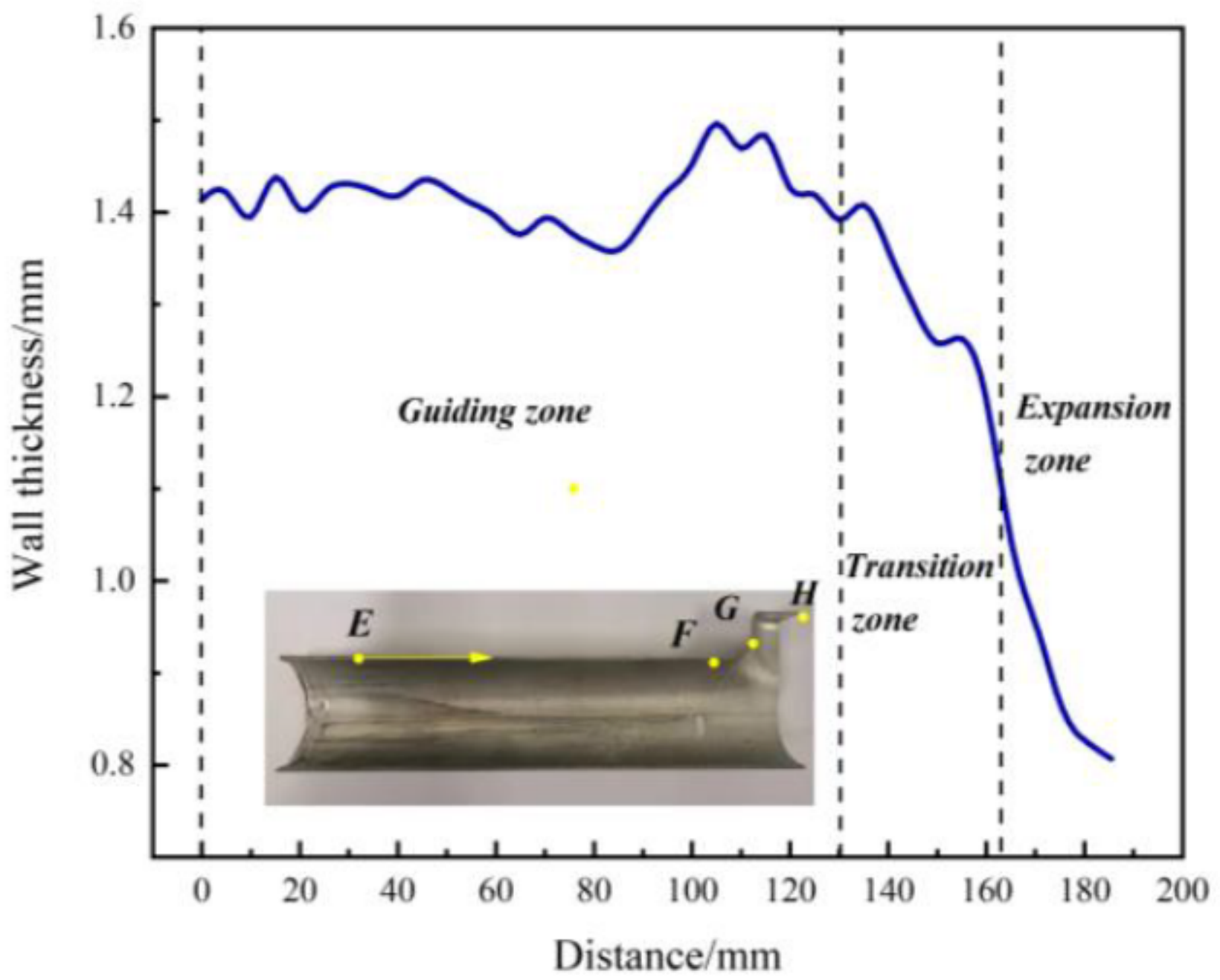

Figure 15

The wall thickness distribution of the three-way tube 


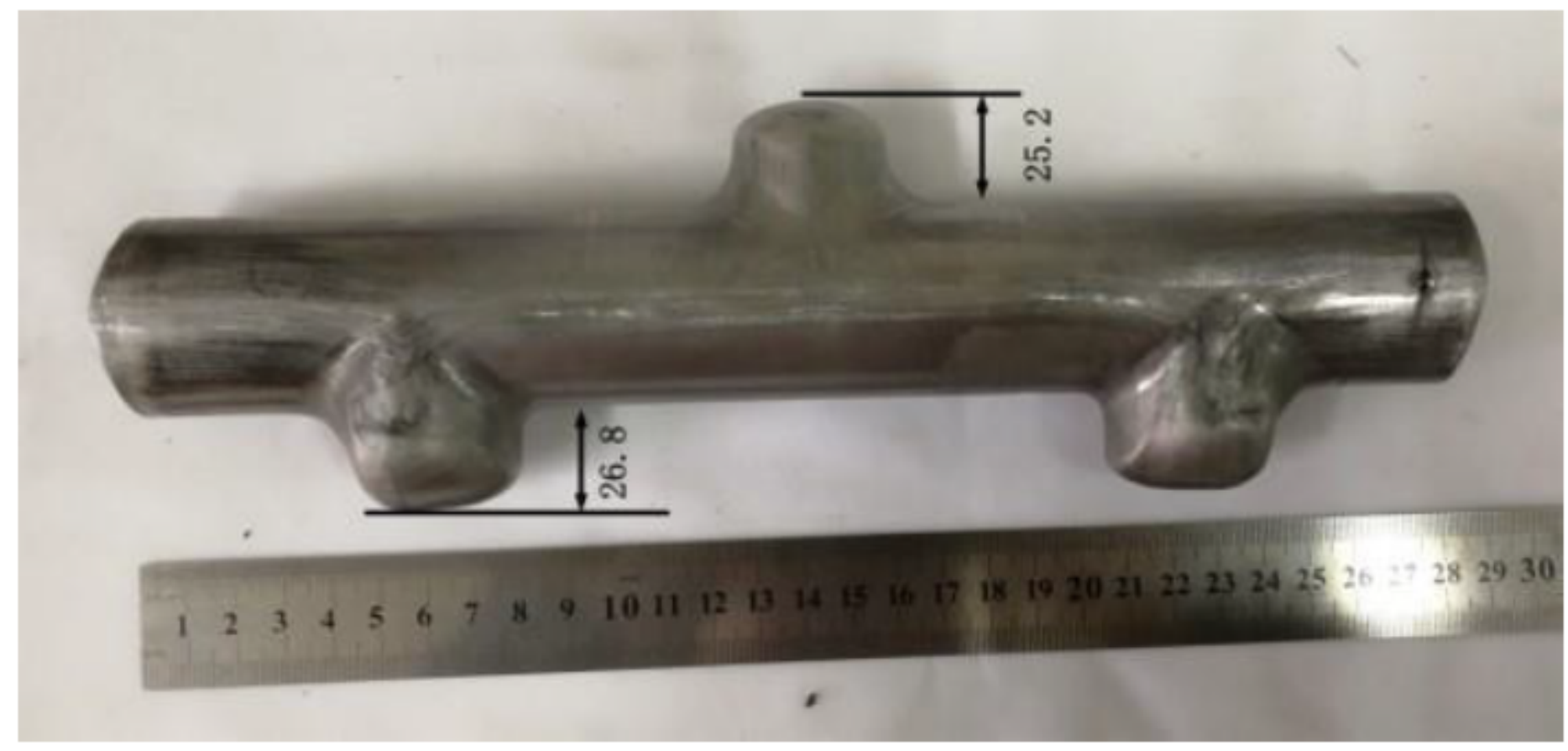

Figure 16

Five-way tube for optimized experiments 


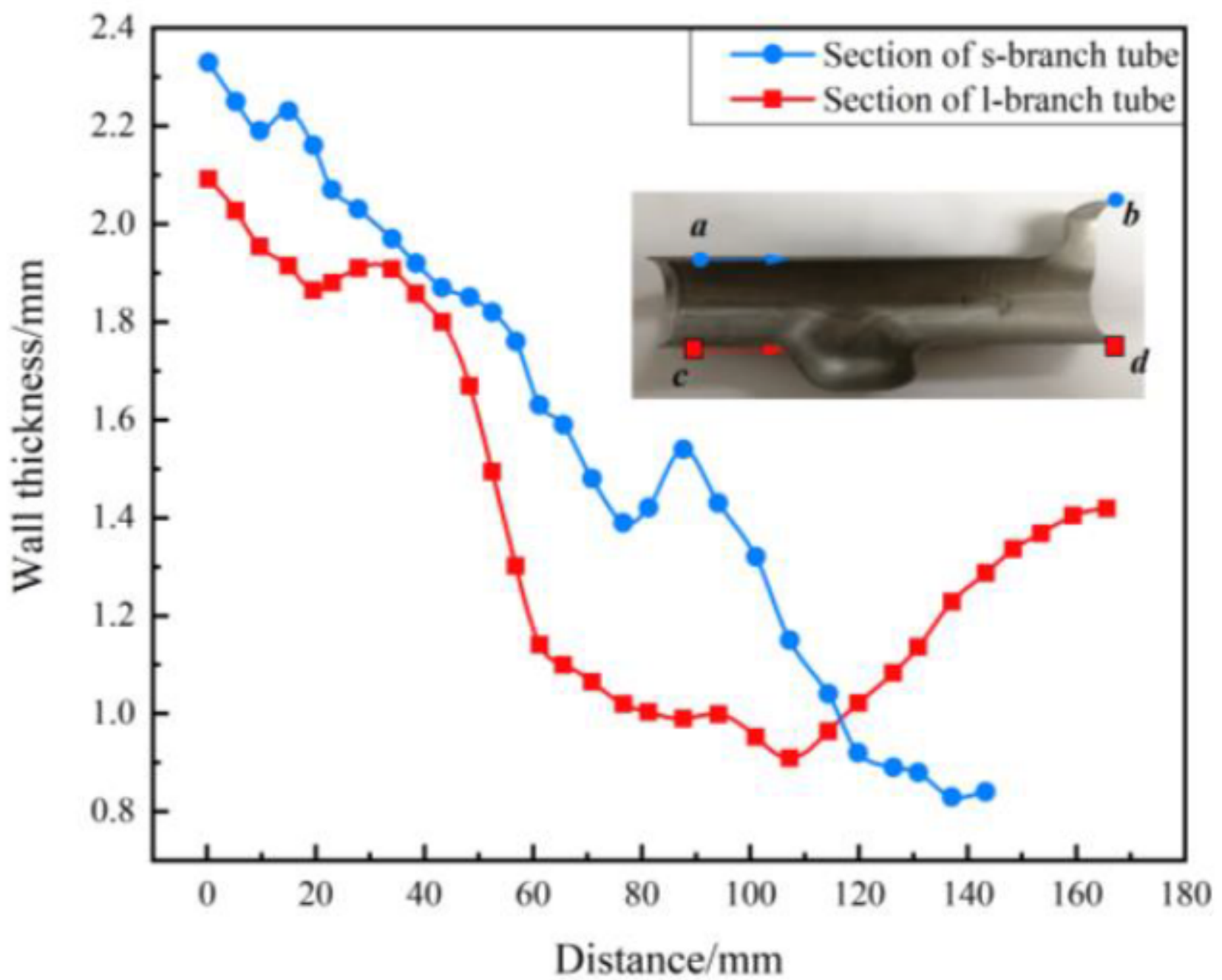

Figure 17

Wall thickness distribution of five-way tube 